\title{
Atopic keratoconjunctivitis: long-term results of medical treatment and penetrating keratoplasty
}

\author{
Ceratoconjuntivite atópica: resultados a longo prazo do tratamento clínico e da ceratoplastia penetrante
}

Yusuf Koçluk ${ }^{1}$, Zuleyha Yalniz-Akkaya ${ }^{1}$, Ayşe Burcu ${ }^{1}$, Firdeves Örnek ${ }^{1}$

\begin{abstract}
Purpose: To evaluate the long-term outcomes of medically or surgically treated patients with atopic keratoconjunctivitis (AKC).

Methods: Charts of 16 patients with AKC (32 eyes) observed between 1996 and 2013 were reviewed retrospectively. Outcome measures included demographic features, follow-up duration, and biomicroscopic findings at the first and most recent visits. The corrected distance visual acuity (CDVA; in decimal units) was evaluated at the initial visit and the 1-,6-, and 12-month follow-up visits.

Results: In the medically treated group (25 eyes of 15 patients), the median follow-up duration was 3 (range, 1-9) years, and the median CDVA values were 0.01 $(0.001-1.0)$ at the first visit and $0.01(0.001-0.8)$ at the most recent visit ( $p=0.916)$. In the penetrating keratoplasty (PK) group (7 eyes of 6 patients), the median follow-up duration was 7 years (range, $1-11$ ), and the median CDVA increased from $0.01(0.001-0.01)$ to $0.2(0.001-0.7)$ postoperatively $(p=0.043)$.

Conclusion: Whereas most AKC patients maintained a useful CDVA with medical treatment, PK may be required in some cases. Despite the frequent occurrence of complications, PK can significantly improve the CDVA.
\end{abstract}

Keywords: Conjunctivitis, allergic/therapy; Conjunctivitis, allergic/surgery; Keratoplasty, penetrating; Treatment outcome

\section{RESUMO}

Objetivo: Avaliar os resultados a longo prazo em ceratoconjuntivite atópica (AKC) pacientes que foram tratados clinicamente ou cirurgicamente.

Métodos: Os prontuários de 16 pacientes (32 olhos) com AKC, que foram acompanhados entre 1996 e 2013 foram avaliados retrospectivamente. As medidas adotadas foram as características demográficas, tempos de seguimento, e resultados biomicroscópicos da visita inicial e da visita mais recente. A acuidade visual corrigida para distância (CDVA), apresentada em unidades decimais, foi avaliada na visita inicial e nas visitas do 10 mês, 6o mês e 10 ano de seguimento.

Resultados: No grupo tratado clinicamente (25 olhos de 15 pacientes), a mediana do tempo de seguimento foi de 3 anos (variação, 1-9) e a CDVA média foi de 0,01 (0,001-1,0) na visita inicial e $0,01(0,001-0,8)$ na visita mais recente $(\mathrm{D}=0,916)$. No grupo de ceratoplastia penetrante (PK) (7 olhos de 6 pacientes), a median a de tempo de seguimento foi de 7 anos (variação, 1-11) e a CDVA média aumentou de 0,01 (0,001-0,01) para 0,2 $(0,001-0,7)(p=0,043)$ no pós-operatório.

Conclusões: Embora a maioria dos pacientes AKC mantém a CDVA útil com o tratamento clínico, alguns necessitam de PK a fim de obter CDVA útil. Embora as complicaçōes pós-PK ocorrem com freqüência, a CDVA pode melhorar significativamente.

Descritores: Conjuntivite alérgica/terapia; Conjuntivite alérgica/cirurgia; Ceratoplastia penetrante; Resultado do tratamento

\section{INTRODUCTION}

Atopic keratoconjunctivitis (AKC) is a bilateral chronic inflammatory disease of the ocular surface and eyelids. The pathomechanism of AKC involves both chronic immunoglobulin (lg) E-mediated mast cell degranulation and immune reactions mediated by $T$ helper 1 (Th1)- and T helper 2 (Th2)-lymphocyte derived cytokines, as well as other inflammatory cells $s^{(1,2)}$. Notably, eosinophils, which are never observed in normal tissues, are present in the substantia propria of patients with AKC and express increased surface levels of activation markers ${ }^{(3)}$. The onset of disease usually occurs from the second through the fifth decades ${ }^{(4)}$.

Itching is the most characteristic symptom and may be accompanied by watering, mucous discharge, redness, blurred vision, photophobia, and pain. Itching and other symptoms may be continuous or more pronounced in certain seasons. Clinical signs include hyperemia of the conjunctiva and episcleral vessels, papillae in the tarsal conjunctiva, and the presence of concomitant blepharitis. Conjunctival scarring with subepithelial fibrosis, fornix foreshortening, sym- blepharon, and corneal ulceration and neovascularization may occur in the most severe cases $^{(5)}$.

For patients with AKC, the topical application of a vasoconstrictor-antihistamine combination might provide transient symptom relief but is unlikely to affect the immunopathologic process or its sequelae. In contrast, the topical administration of steroids, such as prednisolone acetate, may provide some control of symptoms and signs. However, patients must be warned of the potential risks of cataract formation and glaucoma with steroid therapy. To address this risk, previous studies have found that both the oral and topical forms of cyclosporin A (CSA) can effectively treat AKC and reduce the usage of topical steroids ${ }^{(6,7)}$, and steroid-sparing medications, including the mast cell stabilizer sodium cromolyn $4 \%$, have been shown to effectively reduce symptoms ${ }^{(8)}$.

Significant vision loss associated with AKC usually results from pathologic corneal conditions, among which punctate epithelial keratopathy is the most common. Persistent epithelial defects, scarring, microbial ulceration, and neovascularization are the main corneal
Submitted for publication: September 9, 2015

Accepted for publication: July 23, 2016

Ophthalmolgy Clinic, Ministry of Health Ankara Training and Research Hospital, Ankara, Turkey.
Funding: No specific financial support was received for this study.

Disclosure of potential conflicts of interest: None of the authors have any potential conflicts of interest to disclose.

Corresponding author: Yusuf Koçluk. Eye Department, Adana Numune Training and Research Hospital - Adana, 06520 - Turkey - E-mail: kocluk99@gmail.com

Approved by the following research ethics committee: Ankara Training and Research Hospital (\# 0505/13). 
causes of loss of vision. Although penetrating keratoplasty (PK) typically results in similar surface problems (corneal scarring), this procedure has been shown to improve vision in some patients ${ }^{(9)}$. However, no studies comparing the outcomes of medical treatment with those of PK for AKC were identified in the current body of literature. Accordingly, in this study we aimed to compare the long-term visual and other clinical outcomes of AKC patients who received medical or surgical treatment.

\section{METHODS}

This retrospective case-control study, which compared the results of patients with AKC who underwent surgical transplantation with the results of those who received medical treatment, was conducted according to the tenets of the Declaration of Helsinki after receiving institutional board approval. All medical charts of patients with AKC who were followed for at least 1 year between 1996 and 2013 at an ophthalmology clinic of a tertiary care center were reviewed. Patients who were treated only for AKC and its complications were included; those who received other treatments (surgical or medical) for other ocular conditions were excluded. The characteristics of 16 patients (32 eyes) who met the criteria were evaluated in this study.

The outcome measures were demographic features, follow-up duration, corrected distance visual acuity (CDVA; preoperative and 1-, 6-, and 12-month postoperatively), biomicroscopic findings of the first and last visits, and treatment modality (medical or surgical). Signs and results were compared between patients who did and did not undergo PK. The evaluated clinical findings included eczema, blepharitis, meibomianitis, tarsal margin keratinization, trichiasis, madarosis, ectropion, entropion, conjunctival subepithelial fibrosis, fornix foreshortening, symblepharon, giant papillae, follicles, punctate keratitis, neovascularization or conjunctivalization, persistent epithelial defects, filamentary keratitis, stromal scarring, and graft clarity. Visual acuities, which are expressed in decimals throughout the text, were measured using a Snellen chart. The visual acuity of counting fingers was converted to 0.01 decimal values; hand motion was converted to 0.001 decimal values ${ }^{(10)}$.

The medical treatment administered to patients who did not undergo PK comprised topical CSA 4 times daily and preservative-free artificial tears 8 times daily. CSA 0.3\% (prepared by mixing a Sandimmun $50 \mathrm{mg}$ ampule [Novartis AG, Basel, Switzerland] + $15 \mathrm{ml}$ artificial tears) was used prior to 2004; CSA 0.05\% (Restasis, Allergan Inc., Waco, TX, USA) was used after 2004. Treatment was switched from CSA $0.05 \%$ to CSA $0.3 \%$ if needed. During exacerbation periods (2-6 weeks), topical dexamethasone sodium phosphate $0.1 \%$ was applied 4 times daily (Maxidex; Alcon Laboratories, Inc., Fort Worth, TX, USA), and topical anti-histamines and mast cell stabilizers were added to the treatment regimen. Decreasing doses of topical dexamethasone were administered for 2-6 weeks. Systemic anti-histamines were used in intractable cases. Patients with accompanying rhinitis, asthma, and eczema consulted with the relevant clinical department.

All PK procedures were performed for optic purposes and in patients with reduced visual acuity and greater corneal AKC involvement. Patients were made as comfortable as possible via symptom treatment. Gentamicin $40 \mathrm{mg} / 0.5 \mathrm{ml}$ and dexamethasone $4 \mathrm{mg} / 1 \mathrm{ml}$ were injected subconjunctivally at the end of each PK procedure. Postoperatively, all patients received topical ofloxacin (Exocin, Allergan Pharmaceuticals LTD., Mayo, Ireland), topical 0.1\% dexamethasone 8 times daily, topical CSA 0.05\% four times daily, and preservative-free artificial tears hourly. Topical ofloxacin was discontinued after 1 month. Topical dexamethasone was tapered and maintained according to the needs of each patient. Topical CSA and artificial tears were continued throughout the follow-up period.

SPSS for Windows 16.0 (SPSS Inc. Chicago, IL, USA) was used for the statistical analysis. The Kolmogorov-Smirnov test was used to evaluate the normal distributions of variables (ages, follow-up time, sex, clinical findings, symptoms, first and final CDVA, intraocular pressure, complications, and graft clarity). Numerical variables with abnormal distributions were compared using the Mann-Whitney $U$ test, and descriptive statistics are expressed as medians (minimum-maximum). Qualitative variables were compared using the chi-square test, and descriptive statistics are expressed as percentages (\%) and frequencies. A P value $<0.05$ was considered statistically significant.

\section{RESULTS}

The median age of the 16 patients with AKC ( 9 women, 7 men) was 47.50 (range: 16-68) years. The median ages of patients who underwent PK and those who received only medical treatment were 45.0 (20-68) years and 48 (16-68) years, respectively $(p=0.521)$. The patient groups did not differ significantly with regard to follow-up time $(p=0.071)$. Ten (62.5\%) patients had eczema of the eyelids and periorbital skin, 2 (12.5\%) had asthma, and 6 (37.5\%) had rhinitis. All patients had bilateral signs of AKC. The characteristic features of the included patients are presented in table 1.

The most common modes of eyelid involvement were blepharitis (62.5\%) and meibomianitis (62.5\%). The most common corneal finding was corneal opacity (75\%). Elevated intraocular pressure was observed in only 3 (18.7\%) eyes, and all events were post-PK. Associated keratoconus was present in 1 (6.2\%) patient. Other clinical findings in our cohort included punctate keratitis (62.5\%), neovascularization (62.5\%), conjunctival subepithelial fibrosis $(43.7 \%)$, cataract $(37.5 \%)$, persistent epithelial defects (25\%), filamentary keratitis (18.7\%), giant papillae (18.7\%), tarsal margin keratinization (12.5\%), trichiasis (12.5\%), fornix foreshortening (12.5\%), symblepharon (12.5\%), follicles (12.5\%), entropion (6.2\%), and ptosis (6.2\%).

For the 25 eyes that received only medical treatment, the median follow-up duration was 3 (1-9) years, and the median CDVAs at the first and last visits were $0.01(0.001-1.0)$ and 0.01 (0.001-0.8), respectively, a non-significant difference $(p=0.916)$. Similarly the intraocular pressure did not differ statistically between the first and last visits $(p=0.675)$. Patients exhibited greater symptomatic (e.g., itching, eye redness, irritation) stability during medical treatment.

For the 7 eyes ( 6 patients) subjected to PK, the median follow-up duration was 7 (1-11) years. The median preoperative and postoperative CDVAs were $0.01(0.001-0.01)$ and $0.2(0.001-0.7)$, respectively, a significant difference ( $p=0.043$; Table 2). However, only 1 patient did not experience postoperative complications. The complications associated with PK and patients' graft statuses are listed in table 3.

Among all patients, 3 eyes had both initial and final CDVAs $\geq 0.5$, whereas 10 and 15 eyes respectively had initial and final CDVAs $\geq 0.1$. Although only 7 patients initially had a CDVA $\geq 0.1$ in at least 1 eye, 11 patients had achieved this level of vision by the final examination. Regarding treatment modalities, the median initial CDVAs were 0.01 (range, 0.001-0.01) and 0.01 (range, 0.001-1.0) among patients who did and did not undergo PK, respectively, whereas the corresponding median final CDVAs were 0.2 (range, 0.005-0.7) and 0.04 (range, 0.001-0.8), respectively. The differences between the examinations were not statistically significant in either group ( $p=0.175, p=0.253$, respectively). Similarly, the groups did not significantly differ in terms of changes

Table 1. Characteristic features of study patients

\begin{tabular}{lccc}
\hline & $\begin{array}{c}\text { Medically treated } \\
\text { (25 eyes of 15 patients) }\end{array}$ & $\begin{array}{c}\text { PK treated } \\
\text { (7 eyes of 6 patients) }\end{array}$ & P value \\
\hline Age (years), mean \pm SD & $48.9 \pm 16.7$ & $45.8 \pm 16.0$ & 0.521 \\
Female/male & $2 / 4$ & $8 / 70$ & 0.360 \\
RE/LE & $5 / 2$ & $11 / 14$ & 0.200 \\
Follow-up duration & $6.7 \pm 4.2$ & $3.4 \pm 2.3$ & 0.071 \\
(years), mean \pm SD & & & \\
\hline
\end{tabular}

$\mathrm{SD}=$ standard deviation; $\mathrm{RE}=$ right eye; $\mathrm{LE}=$ left eye; $\mathrm{PK}=$ penetrating keratoplasty. 
Table 2. Preoperative and postoperative corrected distance visual acuities of patients who underwent penetrating keratoplasty (PK)

\begin{tabular}{|c|c|c|c|c|c|c|c|}
\hline \multirow[b]{3}{*}{ Patient/eye } & \multirow[b]{3}{*}{ Age/sex } & \multirow[b]{3}{*}{ Follow-up after PK (years) } & \multicolumn{5}{|c|}{ Corrected distance visual acuity (in decimal notation) } \\
\hline & & & \multirow[b]{2}{*}{ Preop } & \multicolumn{4}{|c|}{ Postoperative } \\
\hline & & & & 1 month & 6 month & 1 year & At last visit \\
\hline 1/RE & $39 / \mathrm{F}$ & 2 & 0.010 & 0.01 & 0.100 & 0.300 & 0.300 \\
\hline $1 / L E$ & $39 / F$ & 10 & 0.010 & 0.20 & 0.200 & 0.200 & 0.010 \\
\hline 2/RE & $47 / F$ & 1 & 0.010 & 0.01 & 0.100 & 0.100 & 0.100 \\
\hline $3 / L E$ & 20/M & 4 & 0.010 & 0.10 & 0.600 & 0.300 & 0.200 \\
\hline 6/RE & $45 / F$ & 5 & 0.001 & 0.50 & 0.500 & 0.700 & 0.700 \\
\hline
\end{tabular}

$M=$ male; $F=$ female; $R E=$ right eye; $L E=$ left eye.

Table 3. Postoperative complications and graft statuses in patients treated wtih penetrating keratoplasty

\begin{tabular}{lcccc}
\hline Patients/eye & Graft status* & Graft rejection & Complications & Graft status\# \\
\hline 1/RE & Clear & - & Cataract & Clear \\
$1 / \mathrm{LE}$ & Clear & Yes, irreversible & $\begin{array}{c}\text { Glaucoma and } \\
\text { cataract }\end{array}$ & Opaque \\
& & - & Glaucoma & Clear \\
2/RE & Clear & - & Cataract & Semi-opaque \\
3/LE & Clear & - & Glaucoma and & Semi-opaque \\
4/RE & Semi-opaque & Yes, reversible & cataract & \\
& & - & Cataract & Clear \\
5/LE & Clear & - & - & Clear \\
6/RE & Clear & - & &
\end{tabular}

* = in the first year; $\#=$ at last visit; $R E=$ right eye; $L E=$ left eye.

in intraocular pressure between the initial and final examinations $(p=0.853, p=0.067$, respectively). However, patients who underwent PK were significantly more likely to present with cataracts, anterior sinechias, and glaucoma at the final examination (6 (85.7\%) eyes that underwent PKP vs. 4 (16.0\%) eyes that did not undergo PK; $p<0.001$ ).

The most common complication was cataracts (71.5\%), followed by intraocular pressure elevation; the latter occurred in half of the patients and was controlled with topical medications. Conjunctival and corneal complications at the last visit were statistically more frequent among patients who did not undergo PK $(p<0.001)$; however, this group was larger than the PK group, which might present a statistical limitation.

Graft rejections occurred in 2 patients ( 1 within the first year and 1 after the first year). The graft remained clear in 1 such patients but became opaque in the other. Although $6(85.7 \%)$ grafts remained clear after the first postoperative year, 1 (14.3\%) graft had become semi-opaque. At the final examination, 4 (57.1\%) grafts remained clear, $2(28.6 \%)$ were semi-opaque due to the recurrence of AKC-related corneal scarring, and 1 (14.3\%) graft was opaque consequent to graft rejection. In our series, $57.1 \%$ of grafts were clear at the final visit, and complication rates were high (5/7 cataracts and 3/7 glaucoma).

Amniotic membrane transplantation (AMT) was performed in 6 (18.8\%) eyes (2 for persistent epithelial defects following PK, 4 for primary persistent epithelial defects). Although 1 of those grafts remained clear after AMT, the others healed with varying degrees of subepithelial and stromal opacity. At the last visit, visual acuity was not found to differ according to sex. Patients with a CDVA of $\geq 0.1 \mathrm{had}$ significantly higher final visual acuities $(p=0.036)$.

\section{DISCUSSION}

AKC is a chronic allergic inflammatory disease with bilateral involvement of the cornea and conjunctiva. This disease has an onset during adolescence but primarily affects adults, with a peak incidence between 30 and 50 years of age ${ }^{(11)}$. Accordingly, the median age of our cohort was compatible with the literature. Patients with AKC typically describe severe, persistent, periocular itching associated with dermatitis. There is usually a family history of atopic disease in 1 or both parents, and patients often have another atopic manifestation such as asthma $(65 \%)$ or allergic rhinitis $(65 \%)^{(12)}$. Inversely, the reported incidence of ocular involvement among patients with atopic dermatitis ranges from $25 \%$ to $42 \%{ }^{(4,13-15)}$. In our patients, $62.5 \%$ of patients had eczema of the eyelids and periorbital skin, $12.5 \%$ had asthma, and $37.5 \%$ had rhinitis. The discrepancies between the literature and our results might be related to the small number of patients in our study.

AKC is among the most debilitating allergic conjunctival diseases because of its ability to induce visual losses consequent to corneal complications ${ }^{(16)}$. These complications may be mild or severe and include superficial punctate keratitis, exfoliated superficial punctate keratitis, corneal erosions, and shield ulcers that progress to ulceration and neovascularization, conjunctival subepithelial fibrosis, fornix shortening, and symblepharon formation ${ }^{(16,17)}$. In our study, corneal opacity, corneal neovascularization, punctate keratitis, and persistent epithelial defects were observed in $75 \%, 62.5 \%, 62.5 \%$, and $25 \%$ of patients, respectively.

The immunophilin CSA inhibits T lymphocyte activation by inhibiting the expression of the IL-2 receptor, as well as the activation of eosinophils and mast cells, thereby preventing the release of inflammatory mediators ${ }^{(18,19)}$. A large prospective observational study of patients with vernal keratoconjunctivitis or AKC $(n=594)$ evaluated the efficacy of a CSA $0.1 \%$ aqueous ophthalmic solution. Over a 6 -month period, $30 \%$ of patients were able to discontinue topical steroid use. The most common adverse complaint was eye irritation $(12 \%)$, and $>1 \%$ of patients $(n=5)$ reported infectious complications (e.g., bacterial corneal ulcer or herpetic keratitis) ${ }^{(20)}$. In our study, topical CSA was used as a primary treatment for the long-term prevention of AKC exacerbations and complications. Despite the limited number of cases in our series, 16 patients experienced symptom improvement with CSA treatment, and CDVA remained stable $(p=0.916)$.

Takano et al. ${ }^{(21)}$ observed dramatic healing of a persistent (duration: 6 months) allergic corneal ulcer following amniotic membrane patching in a patient with AKC. In another study, significant decreases in symptoms and complete corneal ulcer re-epithelialization were observed in all cases of chronic AKC within 7 days of treatment ${ }^{(22)}$. In our study, 6 eyes of 6 patients were subjected to AMT for persistent epithelial defects and corneal ulcers, with successful corneal epithe- 
lium recovery in all cases. We believe that AMT should be considered a beneficial adjunctive treatment for cases in which epithelization must be achieved quickly.

Patients with AKC may require corneal transplantation to treat corneal scarring, vascularization, or perforation ${ }^{(9)}$. Although such patients are considered to have a high risk of corneal graft failure, especially in the context of high serum IgE levels ${ }^{(9)}$, some reports in the literature have discussed the prognosis of PK in patients with AKC. In one series of patients with keratoconus who underwent keratoplasty, the outcomes of corneal grafting in the 30 atopic patients were comparable to the outcomes of non-atopic patients ${ }^{(23)}$. Ghoraishi et al. ${ }^{(9)}$ studied 11 eyes in 9 patients with AKC who required PK and evaluated the visual outcomes and prognostic factors. The authors observed a final visual acuity of $\geq 0.5$ in $46 \%$ of the eyes; in addition, the grafts remained clear in 10 eyes, and an average improvement of 4.5 Snellen acuity lines was recorded. Despite the frequent postoperative complications observed in our patients, the CDVA improved significantly after PK. We note, however, that our study was limited by the imbalance in patient numbers between the patient groups and the small number of total patients.

In conclusion, most patients with AKC are able to maintain a useful CDVA with medical treatment and follow-up, as shown by the observation of similar long-term CDVAs in patients with AKC who were treated medically or surgically. However, in some cases PK may be required to achieve a useful CDVA. Although PK is associated with frequent postoperative complications, it has also been shown to yield significant postoperative improvements in CDVA.

\section{REFERENCES}

1. Bonini S. Atopic keratoconjunctivitis. Allergy. 2004;59(78):71-3.

2. Leonardi A, De Dominicis C, Motterle L. Immunopathogenesis of ocular allergy: a schematic approach to different clinical entities. Curr Opin Allergy Clin Immunol. 2007; 7(5):429-35.

3. Hingorani M, Calder V, Jolly G, Buckley RJ, Lightman SL. Eosinophil surface antigen expression and cytokine production vary in different ocular allergic diseases. J Allergy Clin Immunol. 1998:102(5):821-30.

4. Chen JJ, Applebaum DS, Sun GS, Pflugfelder SC. Atopicc Keratoconjunctivitis: A review. J Am Acad Dermatol. 2014;70(3):569-75.

5. Heustein Sy, Leonard Bielory. Atopic keratoconjunctivitis Allergy Asthma Proc. 2013; 34(1):33-41
6. Hoang-Xuan T, Prisant O, Hannouche D, Robin H. Systemic cyclosporin A in severe atopic keratoconjunctivitis. Ophthalmology. 1997;104(8):1715-20.

7. Hingorani M, Moodaley L, Calder VL, Buckley RJ, Lightman S. A randomized, placebocontrolled trial of topical cyclosporin A in steroid-dependent atopic keratoconjunctivitis. Ophthalmology. 1998;105(9):1715-20

8. Avunduk AM, Avunduk AC, Kapıcıoglu Z, Akyol N, Tavli L. Mechanisms and comparison of anti-allergic efficacy of topical lodoxamide and cromolyn sodium treatment in vernal keratoconjunctivitis. Ophthalmology. 2000;107(7):1333-37.

9. Ghoraishi M, Akova YA, Tugal-Tutkun I, Foster CS. Penetrating keratoplasty in atopic keratoconjunctivitis. Cornea. 1995;14(6):610-3.

10. Holladay JT. Visual acuity measurements. J Cataract Refract Surg. 2004;30(2):287-90.

11. O'Brien TP. Allergic conjunctivitis: an uptade on diagnosis and management. Curr Opin Allergy Clin İmmunol. 2013;13(5):543-9.

12. Power WJ, Tugal-Tutkun I, Foster CS. Long-term follow-up of patients with atopic keratoconjunctivitis Ophthalmology. 1998;105(2):637-42.

13. Kaujalgi R, Handa S, Jain A, Kanwar AJ. Ocular abnormalities in atopic dermatitis in Indian patients. Indian J Dermatol venereol Leprol. 2009;75(2):148-51.

14. Moscovici BK, Cesar AS, Nishiwaki-Dantas MC, Mayor SA, Marques JC. Atopic keratoconjunctivitis in patients of the pediatric dermatology ambulatory in a reference center. Arc Bras Oftalmol. 2009;72(6):805-10.

15. Ebihara N, Funaki T, Matsuda H, Okumura K, Muurakami A, Ra C. Corneal abnormalities in the NC/Nga mouse: an atopic dermatitis model. Cornea. 2008:2(8):923-9.

16. Wakamatsu TH, Tanaka M, Satake Y, Dogru M, Fukagava K, Igarashi A, et al. Eosinophil cationic protein as a marker for assessing the efficacy of tacrolimus ophthalmic solution in the treatment of atopic keratoconjunctivitis. Mol Vis. 2011;13(17):932-8.

17. Takamura E, Uchio E, Ebihara N, Ohno S, Ohashi Y, Okamoto S, et al. Japanese guideline for allergic conjunctival diseases. Alergol Int. 2011;60(2):191-203.

18. Daniell M, Constantinou M, Vu HT, Taylor HR. Randomised controlled trial of topical ciclosporin A in steroid dependent allergic conjunctivitis. Br J Ophthalmol. 2006;90(4): 461-4.

19. Akpek EK, Dart JK, Watson S, Christen S, Dursun D, Yoo S, et al. A randomized trial of topical cyclosporin 0.05\% in topical steroid-resistant atopic keratoconjunctivitis. Ophthalmology. 2004;111(3):476-82.

20. Ebihara N, Ohashi Y, Uchio E, Okamoto S, Kumagai N, Shoji J, et al. A large prospective observational study of novel cyclosporine $0.1 \%$ aqueous ophthalmic solution in the treatment of severe allergic conjunctivitis. J Ocular Pharmacol Ther. 2009;25(4):365-72.

21. Takano Y, Fukagawa K, Miyake-Kashima M. Dramatic healing of an allergic corneal ulcer persistent for 6 months by amniotic membrane patching in a patient with atopic keratoconjunctivitis: a case report. Cornea. 2004;23(7):723-5.

22. Rouher N, Pilon F, Dalens H. Implantation of preserved human amniotic membrane for the treatment of shield ulcers and persistent corneal epithelial defects in chronic allergic keratoconjunctivitis. J Fr Ophtalmol. 2004;27(10):1091-7.

23. Kirkness CM, Ficker LA, Steele AD, Rise NS. The success of penetrating keratoplasty for keratoconus. Eye (Lond). 1990;4 (Pt 5):673-88. 